\title{
Genetic Analysis of Body Condition Score in First-Parity Danish Holstein Cows
}

\author{
J. Lassen, ${ }^{\star} \ngtr$ M. Hansen, ${ }^{\star}$ M. K. Sørensen, ${ }^{\star}$ G. P. Aamand, $†$ \\ L. G. Christensen, $\ddagger$ and P. Madsen* \\ *Department of Animal Breeding and Genetics, \\ Danish Institute of Agricultural Sciences, \\ Research Centre, DK-8830 Tjele, Denmark \\ †The Danish Agricultural Advisory Centre, DK-8200 Aarhus N, Denmark \\ fDepartment of Animal Science and Animal Health, \\ The Royal Veterinary and Agricultural University, \\ DK-1870 Frederiksberg C, Denmark
}

\begin{abstract}
The aim of this study was to test whether genetic components for body condition score (BCS) changed during lactation in first-parity Danish Holsteins. Data were extracted from the national conformation scoring system and consisted of 28,948 records from 3894 herds. Cows were scored once during lactation for BCS on a scale from 1 to 9 with increments of 1 . The majority of records were made from d 30 to 150 of lactation. Mean BCS was $4.28 \pm 0.98$. Body condition score was lowest in wk 8 to 10 from calving. A multivariate sire model with BCS recordings in six lactation stages treated as different traits was used to analyze the data. In addition, a random regression sire model was used to evaluate the changes in BCS as continuous functions of lactation stage. Estimates of heritability from the multivariate approach ranged from 0.14 to 0.29 , and the estimated genetic correlations between BCS at different lactation stages were all higher than 0.82 . The random regression model was based on Legendre polynomials (LP) specified on days in milk at scoring. To evaluate the change in mean BCS during lactation, the fixed part of the model included a fifth-order LP on the effect of days in milk at scoring. The highest order of fit used for the sire effect was a third-order LP, but based on likelihood ratio tests this could be reduced to a 0 order, i.e., a model with only the intercept term for the sire effect. This means that the genetic variation is constant over the investigated part of the lactation. Therefore, BCS can be considered the same trait during lactation, and a simple sire model can be used for prediction of breeding values.
\end{abstract}

Received March 18, 2003.

Accepted May 19, 2003.

Corresponding author: J. Lassen; e-mail: jan.lassen@agrsci.dk.
(Key words: body condition score, multivariate model, random regression model, genetic component)

Abbreviation key: LP = Legendre polynomials.

\section{INTRODUCTION}

For many years, the main focus in the selection of dairy cows has been on production traits. This has lead to an increase in production, which is not followed by a corresponding increase in feed intake capacity (Van Arendonk et al., 1991). This results in an increased negative energy balance, which often leads to a poorer reproductive performance (Domecq et al., 1997), increased SCS, mastitis, and other diseases (Heuer et al., 1999; Collard et al., 2000). All of these problems increase the cost of production as well as decrease the welfare of the animal.

Large-scale, direct measurements of energy balance are difficult and expensive to obtain. Therefore, indicators of energy balance are needed. Body condition score is a subjective method of assessing the amount of metabolizable energy stored in fat and muscles (body reserves) in live animals (Ferguson et al., 1994). For decades, BCS has been used as a management tool to indicate the energy balance of cows (Lowman et al. 1976; Waltner et al., 1993; Markusfeld et al., 1997). Recently, studies of the genetics of BCS have been performed. Compared with other type traits, BCS changes dramatically during lactation. A change in genetic effects for BCS during lactation has been shown in earlier studies (Jones et al., 1999; Veerkamp et al., 2001). Other studies suggested that BCS should be considered the same trait during lactation (Dechow et al., 2000; Koenen et al., 2001).

In 2001, BCS was introduced to the Danish conformation scoring system. The objectives of this study were to estimate genetic parameters for BCS in first-parity Danish Holsteins and to determine whether the genetic 


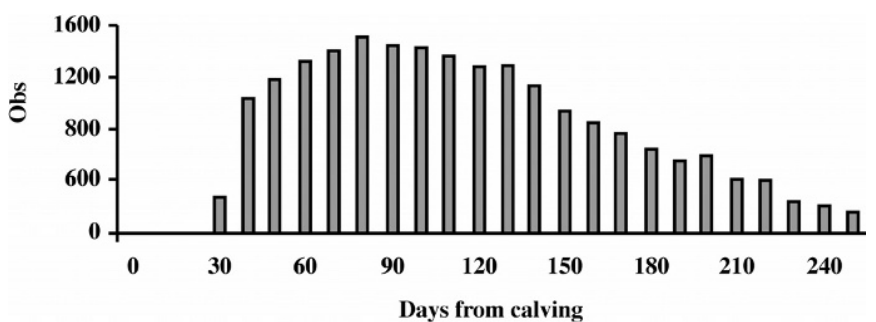

Figure 1. Number of observations for BCS in various 10-d time periods after first calving.

components for BCS change during lactation using data from the national conformation scoring system.

\section{MATERIALS AND METHODS}

\section{Data}

The data were extracted from the Danish National cattle database and contained BCS on first-parity Holstein cows (Danish Cattle, 2003). BCS were scored by professional type classifiers as a part of the regular national conformation scoring of cows. Data included records from April 2001 to March 2002. The BCS classification was performed using the method described by Ferguson et al. (1994), where the amount of body fat tissue under the skin in the thurl, loin, rump, and tailhead area was visually measured. Body condition scores were scored on a scale from 1 to 9 with increments of 1 as all other conformation traits in the Danish system. Ferguson et al. (1994) used a scale from 1 to 5 with increments of 0.25 . Cows that scored low were thin and cows that scored high were fat.

Before editing, the dataset contained 30,625 observations from first parity. In the current evaluation system for type traits, only cows classified before 8 mo after calving are included. Therefore, cows classified later were removed from the dataset. Cows classified by classifiers with fewer than 500 observations were deleted. Also calving age had to be between 21 and 44 mo. After editing, the dataset contained 28,948 observations on daughters from 1208 sires and from 3894 herds. The pedigree for sires was traced from an animal model design and included 6178 animals.

There were very few observations in early lactation (Figure 1). Most of the cows (73\%) were scored between 35 and $150 \mathrm{~d}$ after calving.

\section{Models}

Data were analyzed using a multivariate sire model in which BCS at different stages of lactation were treated as different traits and using a random regres- sion sire model that allows for changes during lactation in both the fixed and random effects. For both models (co)variance components were estimated using the AIREML algorithm (Jensen et al., 1997) in the DMUpackage (Madsen and Jensen, 2000).

\section{Multivariate Model}

The dataset was split into six periods $(<60,61$ to 90 , 91 to 120,121 to 150,151 to 180 , and 181 to 240 DIM). Recordings in these periods were considered as separate traits in the following model:

$$
\mathbf{y}_{\mathrm{i}}=\mathbf{X}_{\mathrm{i}} \mathbf{b}_{\mathrm{i}}+\mathbf{Z}_{\mathrm{i}} \mathbf{s}_{\mathrm{i}}+\text { ei, } \mathrm{i}=1, \ldots, 6
$$

where $\mathbf{y}_{\mathrm{i}}$ is the observations for BCS in period i. $\mathbf{X}_{\mathrm{i}}$ is the design matrix relating the vector of fixed effects in $\mathbf{b}_{\mathrm{i}}$ to $\mathbf{y}_{\mathrm{i}} . \mathbf{Z}_{\mathrm{i}}$ is the design matrix relating the random effects of sires in vector $\mathbf{s}_{\mathrm{i}}$ to $\mathbf{y}_{\mathrm{i}}$. The vector of residuals for period $\mathrm{i}$ are represented by $\mathbf{e}_{\mathrm{i}}$.

The fixed effects for all submodels were: herd (3894 levels), season (two levels), classifier (five levels), and age at calving in months (24 levels). The fixed effects also included regressions on DIM, expected heterozygosity between Holstein Friesian and original Danish Black and White in each cow and on percent Holstein Friesian genes in each cow.

The assumption for the random effects was:

$$
(\mathbf{s}) \sim N\left(\mathbf{0} ;\left[\begin{array}{ccc}
\mathbf{G}_{0} \otimes \mathbf{A} & \mathbf{0} \\
\mathbf{0} & \mathbf{R}_{0} \otimes \mathbf{I}
\end{array}\right]\right)
$$

where $\mathbf{G}_{0}$ is a $6 \times 6$ matrix containing the (co)variance components of the sire effect and $\mathbf{A}$ is the additive genetic relationship matrix for the sires. $\mathbf{R}_{0}$ is a $6 \times 6$ matrix with the variance of the residuals in the diagonals and zeroes in the off diagonals and $\mathbf{I}$ is an identity matrix of proper size, depending on the number of records. The diagonal structure of $\mathbf{R}_{0}$ is due to the fact that a cow is only scored once during lactation.

\section{Random Regression Model}

Because each cow had only one observation for BCS, a random regression sire model was applied.

$$
\mathbf{y}=\mathbf{X}_{(1)} \beta+\mathbf{X}_{(2)} \mathbf{b}+\mathbf{Z s}+\mathbf{e},
$$

where $\mathbf{y}$ is the observations for BCS. $\mathbf{X}_{(1)}$ is the design matrices relating the fixed effects in $\beta$ to $\mathbf{y}$.

The effects in $\beta$ were the same as for the fixed effects included in the multivariate model except for the linear regressions on DIM. $\mathbf{X}_{(2)}$ is a design matrix of Legendre 


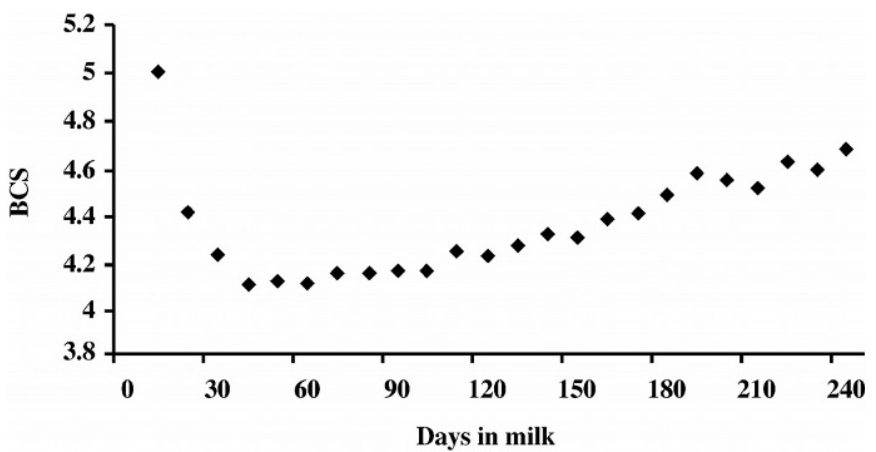

Figure 2. Simple means for BCS in various periods after first calving.

polynomials (LP) up to fifth order, evaluated at the specified DIM at classification and $\mathbf{b}$ is the fixed regression coefficients on DIM at classification. $\mathbf{Z}$ is a design matrix of LP up to the third order evaluated at the specified DIM at classification and $\mathbf{s}$ is the random regression effect of sire. The residuals are represented by $\mathbf{e}$.

$\operatorname{Var}[\mathbf{s}]=\mathbf{G}=\mathbf{G}_{\mathbf{0}} \otimes \mathbf{A}$, where $\mathbf{A}$ is the relationship matrix and $\mathbf{G}_{\mathbf{0}}$ is the additive genetic (co)variance matrix.

$\mathbf{G}_{\mathbf{0}}$ can be written as

$$
\mathbf{G}_{\mathbf{0}}=\left[\begin{array}{cccc}
\sigma_{g 1}^{2} & \sigma_{g 1 g 2} & \ldots & \sigma_{g 1 g j} \\
\sigma_{g 2 g 1} & \sigma_{g 2}^{2} & \ldots & \sigma_{g 2 g j} \\
\vdots & \vdots & \ddots & \vdots \\
\sigma_{g j g 1} & \sigma_{g j g 2} & \ldots & \sigma_{g j}^{2}
\end{array}\right]
$$

where $\mathrm{j}$ is the number of coefficients in the random regression for the sire effect (i.e., the order of fit plus one).

$\operatorname{Var}[\mathbf{e}]=\mathbf{R}=\sigma_{\mathbf{e}}^{2} \otimes \mathbf{I}, \mathbf{I}$ was an identity matrix of proper size.

Residual variances were assumed homogeneous across the lactation.

To test higher-order covariance functions for sire effects compared with lower-order covariance functions, a likelihood ratio test was performed. Significance levels for the fixed effects were defined when the difference in estimates was more than two standard deviations.

\section{RESULTS}

\section{Phenotypic Means}

The overall mean for BCS was $4.28 \pm 0.98$. The level of BCS was highest at early lactation (5.0) and lowest between d 40 and 70 from calving (4.1) (Figure 2). Body

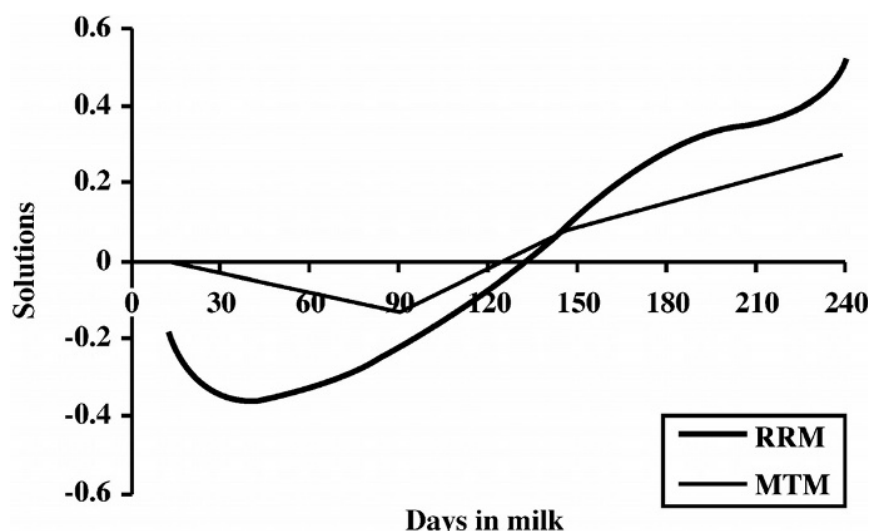

Figure 3. Solutions for fixed effect of days in milk from random regression model (RRM) with only an intercept term for the sire effect and a fifth-order Legendre polynomial for DIM. Regressions for fixed effect of for six lactation periods from the multitrait model (MTM).

condition score increased gradually after reaching a minimum around d 70 .

\section{Fixed Effects}

A fifth-order Legendre polynomial was fitted to the fixed effect of DIM in the random regression models. Solutions for this effect show similar patterns to the phenotypic observations (Figure 3). Solutions for DIM were lowest around $\mathrm{d} 40$ and increased during the rest of the lactation.

Age at calving had a significant effect on BCS. The mean of BCS was about 0.6 higher for heifers calving at 41 mo compared with heifers calving at $20 \mathrm{mo}$. None of the models showed a significant effect of heterozygosity or percentage of Holstein Friesian genes on BCS. There was a tendency that cows with a low degree of heterozygosity between original Danish Black and White and Holstein Friesian scored low for BCS. Also, there was a tendency for cows with a high percentage of Holstein Friesian genes to score lower for BCS compared with cows with high percentage of original Danish Black and White genes. Cows scored lower in summer than in winter. In the multivariate model, regression on DIM was negative in the first two periods and positive in the last four periods.

\section{Multivariate Analysis}

Estimated sire variance was highest (0.048) in the period from 61 to $90 \mathrm{DIM}$ and lowest $(0.021)$ in the period from 121 to $150 \mathrm{DIM}$. Estimates of sire variances in all other periods were not significantly different from each other (Table 1). The residual variance for BCS was not significantly different between the six lactation periods. 
Table 1. Estimates of means, sire, and residual variances and heritabilities with standard errors, for BCS in different periods from multivariate model.

\begin{tabular}{llllll}
\hline Number observed & Period & Mean & $\sigma_{\mathrm{s}}^{2}$ & $\sigma_{\mathrm{e}}^{2}$ & $\mathrm{~h}^{2}$ \\
\hline 4729 & $<60$ & 4.12 & $0.030(0.009)$ & $0.61(0.02)$ & $0.19(0.06)$ \\
6128 & $61-90$ & 4.14 & $0.048(0.010)$ & $0.61(0.01)$ & $0.29(0.06)$ \\
5883 & $91-120$ & 4.19 & $0.029(0.008)$ & $0.59(0.01)$ & $0.19(0.05)$ \\
4963 & $121-150$ & 4.27 & $0.021(0.007)$ & $0.60(0.02)$ & $0.14(0.05)$ \\
3508 & $151-180$ & 4.41 & $0.043(0.015)$ & $0.61(0.02)$ & $0.26(0.09)$ \\
3737 & $181-240$ & 4.58 & $0.037(0.014)$ & $0.66(0.02)$ & $0.21(0.08)$ \\
$28,948^{1}$ & $13-240$ & 4.28 & $0.032(0.004)$ & $0.63(0.006)$ & $0.20(0.02)$ \\
\hline
\end{tabular}

${ }^{1}$ Results from random regression model with the sire variance described as an intercept term.

Heritability estimates varied from 0.14 to 0.29 with standard errors of 0.05 to 0.09 (Table 1). The heritability was highest 61 to $90 \mathrm{~d}$ after calving and lowest 121 to $150 \mathrm{~d}$ after calving. Estimates of genetic correlations were all 0.84 or higher (Table 2). No clear pattern was detected in the correlations.

\section{Random Regression Model}

Based on the results of the multivariate model, it seems reasonable to treat the residual variance as homogenous in the random regression approach. The highest-order polynomial was a third-order random LP for the sire effect and a fifth-order LP for the fixed effect of DIM. Only the random effect of sire was tested for each model. Testing each model against a model with a lower order LP showed no significant differences between the four models (Table 3). None of the higher ordered models fit the data better than the simple model, assuming a constant sire effect across lactation.

The heritability estimate for BCS from the model that included only the intercept term was 0.20 . The sire variance was 0.032 , and the residual variance was 0.63 . The heritability estimates for the models with different order for the sire effect were all between 0.18 and 0.27 (Figure 4).

Genetic correlations between BCS on different days during lactation, assuming a third-order polynomial for the sire effect, are shown in Figure 5. For each order, the correlation estimates were always higher than 0.82 . Similar figures were obtained when lower-order polynomials were fit to the data.

\section{DISCUSSION}

\section{Genetic Components}

The results of this study showed that the genetic components for BCS did not change during the lactation period that was investigated. Body condition scores recorded from 30 to $240 \mathrm{~d}$ after calving can therefore be considered the same trait. The genetic correlations (all higher than 0.82) together with the relative high standard errors on the genetic correlations suggested that none of the correlations could be interpreted as being significantly different from 1.0. Results from the random regression model showed that models with highorder polynomials fit to the random sire effect were not significantly better than the simplest model that only included an intercept term. These results suggest that the same genes affect BCS from 30 to $240 \mathrm{~d}$ after calving, and that the effects of these genes do not change over this period.

The high genetic correlations between periods indicate that change in genetic variation of BCS during lactation is limited. In terms of heritability and correlations the results presented are in agreement with former studies on BCS changes (Jones et al., 1999; Dechow

Table 2. Estimates of genetic correlations for BCS in different lactation periods ${ }^{1}$ from random regression model (above diagonal) and multivariate model (below diagonal). Standard errors were only obtained in the multivariate model.

\begin{tabular}{|c|c|c|c|c|c|c|}
\hline DIM & $<60$ & $61-90$ & $91-120$ & $121-150$ & $151-180$ & $181-240$ \\
\hline$<60$ & & 0.93 & 0.84 & 0.82 & 0.85 & 0.91 \\
\hline $61-90$ & $0.93(0.10)$ & & 0.97 & 0.97 & 0.92 & 0.87 \\
\hline $91-120$ & $0.85(0.14)$ & $0.98(0.08)$ & & 0.99 & 0.94 & 0.85 \\
\hline $121-150$ & $0.98(0.17)$ & $0.98(0.11)$ & $0.94(0.15)$ & & 0.98 & 0.94 \\
\hline $151-180$ & $0.96(0.12)$ & $0.91(0.14)$ & $0.88(0.18)$ & $0.98(0.21)$ & & 0.96 \\
\hline $181-240$ & $0.85(0.18)$ & $0.98(0.14)$ & $1.00(0.16)$ & $0.93(0.17)$ & $0.84(0.19)$ & \\
\hline
\end{tabular}

\footnotetext{
${ }^{1}$ In the random regression model correlations were estimated between $\mathrm{d} 30,75,105,135,165$, and 210 in milk.
} 
Table 3. Likelihood ratio tests of the random regression model fit.

\begin{tabular}{llll}
\hline Curve fit & $\begin{array}{l}\text { Difference in } \\
-2 \text { log likelihood }\end{array}$ & $\begin{array}{l}\text { Difference in } \\
\text { parameters }^{1}\end{array}$ & $P$-value \\
\hline Cubic $\Rightarrow$ Quadratic & 1.455 & 4 & 0.83 \\
Quadratic $\Rightarrow$ Linear & 3.238 & 3 & 0.36 \\
Linear $\Rightarrow$ Intercept & 0.305 & 2 & 0.86 \\
\hline
\end{tabular}

${ }^{1}$ Number of parameters in (co)variance matrix for random effect.

et al., 2000; Koenen et al., 2001; Gallo et al., 2001). The results from the multivariate model did not show the same decreasing pattern in genetic correlations when the time period distance was increased.

Fitting a high-order random regression model to the data assumes that the genetic variance can be described by a specific high order LP. Even though there is a covariance between the parameters, this assumption still has influence on the result. This is probably the reason why the third-order LP gives a high estimate for the heritability compared with the other models in early lactation, where there were few observations (Figure 4). This assumption also causes the results at $240 \mathrm{~d}$ from calving, where the estimate for the heritability for the third-order model is decreasing, whereas the estimate for the second-order model is increasing. There were no significant effects of either heterozygosity between original Danish Black and White and Holstein Friesian or percentages of Holstein Friesian genes. The average percentage of Holstein Friesian genes in the cows was 0.95 and, therefore, it is hard to estimate the difference between the two breeds. Koenen et al. (2001) found a significant difference between original Dutch Black and White and Holstein Friesians in a dataset with a lower average percentage of Holstein Friesian genes in the cows compared with the data in this study. The same difference was found in this data but it was not significant.

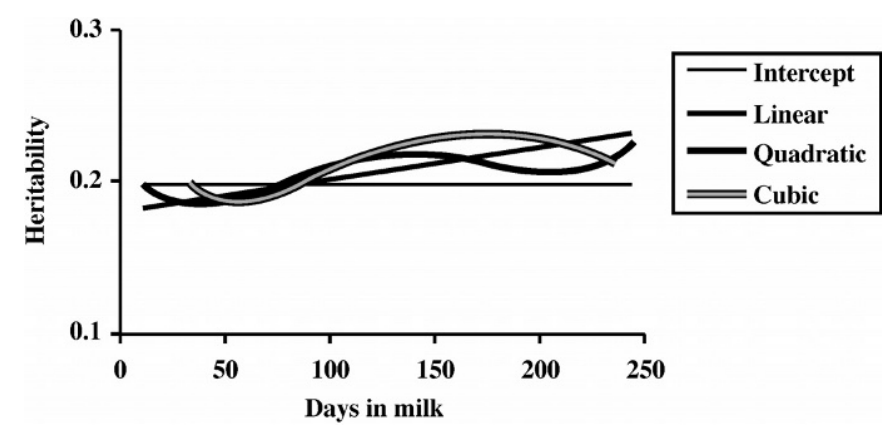

Figure 4. Heritability estimates during lactation for various curves using random regression models.

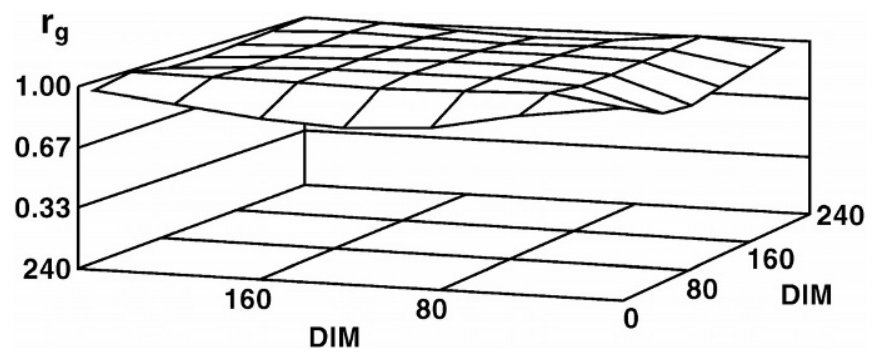

Figure 5. Genetic correlations $\left(r_{g}\right)$ for BCS between DIM with third-order fit describing the effect of sire from random regression model.

\section{Changes in BCS}

During lactation, BCS is considered a very dynamic trait (Broster and Broster, 1998). Simple mean of BCS showed that cows are classified highest in early lactation and lowest 40 to $70 \mathrm{~d}$ from calving. The change from the period with the lowest records to the period with the highest records was in agreement with the results shown by Domecq et al. (1997), Dechow et al. (2000), and Koenen et al. (2001).

Evaluating the trait in early and late lactation was impossible because there were few observations in the data and no data during the dry period. Jones et al. (1999) and Veerkamp et al. (2001) fit a cubic random regression model on datasets from United Kingdom and The Netherlands, respectively. These datasets included observations in early lactation and more observations than our study. Our data indicates that BCS is a homogeneous trait in the period from 30 to 240 DIM.

\section{Further Research}

Recent studies on large datasets suggest a favorable genetic relationship between BCS and fertility traits (Dechow et al., 2000; Pryce et al., 2002). Studies are needed to evaluate the use of BCS as an indicator trait for diseases and mastitis, as well as for feed intake and feed efficiency. Also, studies on the genetic relationship between BCS and persistency are needed.

\section{CONCLUSIONS}

Analyzing data from the national conformation scoring system indicated that genetic contributions to BCS in first parity did not change over the lactation. Heritability estimates for BCS were moderate and between 0.14 and 0.29. Estimates of genetic correlations between various periods of lactation were all higher than 0.82 . Therefore, BCS can be considered a single homogeneous trait in the period from 30 to 240 DIM during first lactation. 


\section{REFERENCES}

Broster, W. H., and V. J. Broster. 1998. Body score of dairy cows. J. Dairy Res. 65:155-173.

Collard, B. L., P. J. Boettcher, J. C. M. Dekkers, D. Petitclerc, and L. R. Schaeffer. 2000. Relationship between energy balance and health traits of dairy cattle in early lactation. J. Dairy Sci. 83:2683-2690.

Danish Cattle. 2003. Principles of Danish cattle breeding. http:// www.lr.dk/kvaeg/diverse/principles.pdf.

Dechow, C. D., G. W. Rogers, and J. S. Clay. 2000. Heritabilities and correlations among body condition scores, production traits, and reproductive performance. J. Dairy Sci. 84:266-275.

Domecq, J. J., A. L. Skidmore, J. W. Lloyd, and J. B. Kaneene. 1997. Relationship between body condition scores and conception at first artificial insemination in a large dairy herd of high yielding Holstein cows. J. Dairy Sci. 80:113-120.

Ferguson, J. D., D. T. Galligan, and N. Thomsen. 1994. Principal descriptors of body condition score in Holstein cows. J. Dairy Sci. 77:2695-2703.

Gallo, L., P. Carnier, M. Cassandro, R. Dal Zotto, and G. Bittante. 2001. Test-day genetic analysis of condition score and heart girth in Holstein Friesian cows. J. Dairy Sci. 84:2321-2326.

Heuer, C., Y. H. Schukken, and P. Dobbelaar. 1999. Postpartum body condition score and results from the first test day milk as predictors of disease, fertility, yield and culling in commercial dairy herds. J. Dairy Sci. 82:295-304.

Jensen, J., E. A. Mäntysaari, P. Madsen, and R. Thompson. 1997. Residual maximum likelihood estimation of (co)variance compo- nents in multivariate mixed linear models using average information. J. Ind. Soc. Agric. Stat. 49:215-236.

Jones, H. E., I. M. S. White, and S. Brotherstone. 1999. Genetic evaluation of Holstein Friesian sires for daughter condition-score changes using a random regression model. Anim. Sci. 68:467-475.

Koenen, E. P. C., R. F. Veerkamp, P. Dobbelaar, and G. De Jong. 2001. Genetic analysis of body condition score of lactating Dutch Holstein and Red-and-White heifers. J. Dairy Sci. 84:1265-1270.

Lowman, B. G., N. A. Scott, and S. H. Somerville. 1976. Condition scoring of cattle. Bull. No. 6. East of Scotland Coll. of Agric., Edinburgh, Scotland.

Madsen, P., and J. Jensen. 2000. DMU: A user's guide. A package for analysing multivariate mixed models. Version 6 , release 4., DJF, Foulum, Denmark.

Markusfeld, O., N. Galon, and E. Ezra. 1997. Body condition score, health, yield and fertility in dairy cows. Vet. Rec. 141:67-72.

Pryce, J. E., M. P. Coffey, S. Brotherstone, and J. A. Wooliams. 2002. Genetic relationships between calving interval and body condition score conditional on milk yield. J. Dairy Sci. 85:1590-1595.

Van Arendonk, J. A. M., G. J. Nieuwhof, H. Vos, and S. Korver. 1991. Genetic aspects of feed intake and efficiency in lactating dairy heifers. Livest. Prod. Sci. 29:263-275.

Veerkamp, R. F., E. P. C. Koenen, and G. De Jong. 2001. Genetic correlations among body condition score, yield and fertility in first-parity cows estimated by random regression models. J. Dairy Sci. 84:2327-2335.

Waltner, S. S., J. P. McNamara, and J. K. Hillers. 1993. Relationships of body condition score to production variables in high producing Holstein dairy cattle. J. Dairy Sci. 76:3410-3419. 